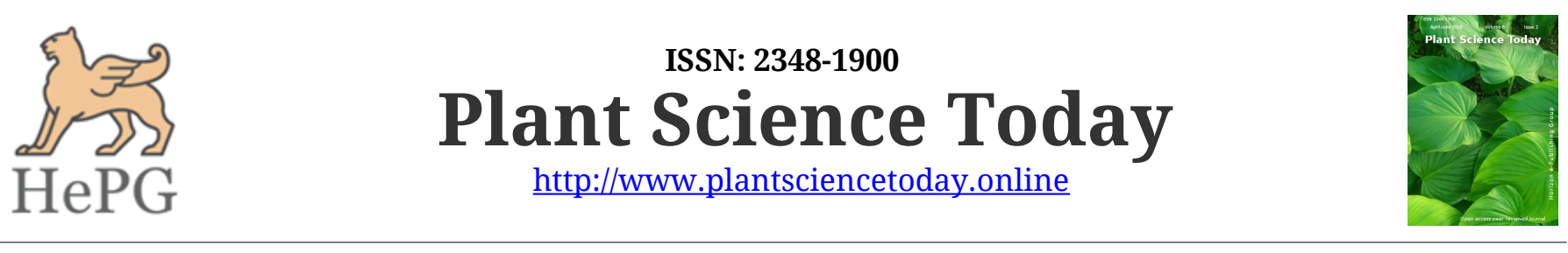

OPEN ACCESS

Review Article

\title{
Surgery and Medicinal Plants: A review of important indigenous medicinal plants of Iran for burn wound healing
}

\author{
Masoud Sharifian $^{1}$, Afshin Hasanvand ${ }^{2}$, Gholam Basati ${ }^{3}$ \& Saber Abbaszadeh ${ }^{4}$ \\ ${ }^{1}$ Department of Surgery, School of Medicine, Lorestan University of Medical Sciences, Khorramabad, Iran \\ ${ }^{2}$ Student Research Committee, Lorestan University of Medical Sciences, Khorramabad, Iran \\ ${ }^{3}$ Clinical Microbiology Research Center, Ilam University of Medical Sciences, Ilam, Iran \\ ${ }^{4}$ Razi Herbal Medicines Research Center \& Hepatitis Research Center, Lorestan University of Medical Sciences, Khorramabad, Iran
}

\section{Article history}

Received: 12 April 2019

Accepted: 09 May 2019

Published: 02 June 2019

\section{Publisher}

Horizon e-Publishing Group

\section{*Correspondence}

Saber Abbaszadeh

$\triangle$ saberabaszade1370@gmail.com

\begin{abstract}
Surgical Science is one of the branches of medical science that deals with surgical and medicinal interventions, which can cure surgical wounds, cuts, burns and so on. The accelerated recovery process has always been a concern for surgeons and physicians. Standard local antibiotic drugs such as silver nitrate, mafenide acetate, sulfadiazine silver and AgNO3 are also used to treat wounds which are associated with some complications. Considering the fact that no effective herbal remedy has been introduced for wound healing, the purpose of this review is to investigate and identify indigenous Iranian herbs used for wound healing after surgery, especially burn wounds. In this systematic review paper, published articles in the period 1952 to 2017 with keywords of surgery, wound healing, burns, herbs, etc. from databases such as SID, MEDLIB, ProQuest, Magiran, Europe PubMed Central and Google Scholar. Abstract and title of all articles were studied and non-relevant articles were deleted and remaining articles were used for review. Based on the results of the study, Malva sylvestris, Camellia sinensis, Aloe vera, Cydonia oblonga, Scrophularia striata, Centella asiatica, Arnebia euchroma, Calendula officinalis and Hypericum perforatum are the most important herbal remedies for burn restoration. The following is an explanation of the most important herbal remedies for native burn wounds in Iran.
\end{abstract}

Keywords: Surgery; Wound; Burn; Medicinal plants; Iran

Citation: Sharifian M, Hasanvand A, Basati G, Abbaszadeh S. Surgery and medicinal plants: A review of important indigenous medicinal plants of Iran for burn wound healing. Plant Science Today 2019;6(2):264-269. https://doi.org/10.14719/pst.2019.6.2.552

Copyright: (c) Sharifian et al (2019). This is an open-access article distributed under the terms of the Creative Commons Attribution License, which permits unrestricted use, distribution, and reproduction in any medium, provided the original author and source are credited (https://creativecommons.org/licenses/by/4.0/).

Indexing: Plant Science Today is covered by Scopus, Web of Science, BIOSIS Previews, ESCI, CAS, AGRIS, CABI, Google Scholar, etc. Full list at http://www.plantsciencetoday.online

\section{Introduction}

Surgery is one of the branches of medicine that along with surgical and pharmacotherapeutic interventions can treat surgical wounds, cuts and burns, etc. The continuous development of new information in surgery has led progression of surgical treatments (1). Wound is an inevitable event in life. It can occur due to microbial infection, physical or chemical damages. Wound healing is commonly impaired by disturbance in the normal process of wound repair and treatment, and excess 
or deficient healing (2). One of the goals of surgery and medicine is wound healing in shorter time and with less complications (3). Wounds have different types and are caused for various reasons for example burn wounds, surgical wounds, cuts, wounds due to infectious agents, etc. Burn wound is one of the most important wounds. One of the major causes of death and disability in the world is due to burn and its complications. Burn is defined as tissue damage caused by factors such as heat, chemicals, electricity, sunlight and nuclear radiation. Most burns are caused by building fires, contact with boiling water, water vapor, flammable liquids and gases. Acceleration of burn healing has always been a concern for surgeons and doctors (4). Approximately 1,200,000 people per year in the United States experience burn requiring treatment (5). If burn is infected, the entire skin in the affected area may be lost, where a skin graft is needed; in these wounds, after the healing, permanent color changes appear in the skin (6). Repair of skin lesions is largely dependent on the restorative role of fibroblast cells and the regeneration of an extracellular environment that contains a high amount of collagen (7). Standard topical antibiotic drugs such as silver nitrate, mafenide acetate and silver sulfadiazine are also used to treat wounds yet they may cause certain complications $(8,9)$. Currently one of the most common antibiotic drug used for burns is sulfadiazine cream which causes many side effects including lack of penetration into the wound, resistance to gram-negative microorganisms, delayed repair of small burn wounds due to decreased pigmentation and epithelization (10). Increased rate of wound healing has many desirable health and economic effects. The rate of wound infection decreases with increasing the rate of wound restoration, and in this way the overall wound healing process will be accelerated (11). From ancient time the preparation of the ointment has been considered for the relief of pain and accelerating recovery of burn wounds by the medical community.

In spite of the therapeutic effects of synthetic drugs, the tendency of people to use these drugs has been decreasing day by day due to their unwanted side effects, and on the other hand tendency to use drugs of natural origin has increased. Medicinal plants are a rich source of various compounds that can be effective in the treatment of infectious and noninfectious diseases, as well as acute and chronic diseases (12-18). Considering the fact that no effective herbal drug has been introduced for healing wounds, the purpose of this review is to investigate and report indigenous medicinal plants of Iran used for healing wounds after surgery especially burn wounds.

\section{Methodology}

In this systematic review paper, published articles were selected for the period 1952 to 2017 with keywords of surgery, wound healing, burns, herbs, etc. from databases such as SID, MEDLIB, ProQuest, Magiran, Europe PubMed Central and Google Scholar. Abstract and title of all articles were studied and non-relevant articles were deleted.

\section{Results}

Based on the results of this review the medicinal plants i.e. Malva sylvestris, Camellia sinensis, Aloe vera, Cydonia oblonga, Scrophularia striata, Centella asiatica, Arnebia euchroma, Calendula officinalis and Hypericum perforatum are effective in restoring burns. The following is an explanation of these medicinal plants for restoring burn wounds.

\section{Malva sylvestris}

In a study conducted by Pirbalouti et al. (19), the extract of the Malva sylvestris caused an increase in connective tissues such as collagen, high levels of fibroblast cells, and a decrease in inflammatory cells in the wound area, and was as effective in healing wound as that of the control group. In a study by Barros et al. (20), the efficacy of treatment was evaluated based on reduction in burn wound area and histopathologic characteristics of $M$. sylvestris and the results showed increased collagen regeneration, increased fibroblast cells and reduced inflammatory cells in improving the wound healing process (20). Another study also showed considerable antioxidant properties of $M$. sylvestris which is due to the presence of polyphenols, vitamins C and A (21). In the study of Nasiri et al., the $M$. sylvestris was observed to effectively prevent leukemia, secretion, erythema and other complications due to burns (22).

\section{Camellia sinensis}

The results of the study by Asadi et al. (23) on the $C$. sinensis (green tea) extract showed a significant reduction in the area of burn wound because of its antibacterial, antioxidant and anti-inflammatory properties. Increased collagen synthesis is also observed and it is due to the polyphenolic compounds called catechin in the leaf extract of green tea. The results of Fatemi et al. (24) showed that green tea extract has antioxidant and antiinflammatory properties due to the presence of polyphenols and has a positive effect on accelerating the repair and contraction of the wound.

\section{Aloe vera}

It was found that $A$. vera gel containing herbal anti-inflammatory agents and thromboxane inhibitors prevent vasoconstriction and improves wound repair process by exerting antiinflammatory properties, boosting the immune system, producing positive effects on gramnegative and gram-positive bacteria and exerting antiviral effect. Due to these effects, the gel is a suitable dressing for burn wounds (25). In the 
studies, $A$. vera has been used to inhibit thromboxane (a healing wound inhibitor), leading to progression of healing and reduction of wound inflammation. $A$. vera has been reported to be effective against a wide spectrum of bacteria such as Pseudomonas aeruginosa, Escherichia coli, Salmonella typhi, Streptococcus pyogenes and Staphylococcus aureus (26). The gel of this plant contains an anti-inflammatory agent called salicylate and inhibitors of formation of thromboxane (as a vasoconstrictive agent) as well as carboxypeptidase, which inhibits bradykinin as a pain-causing agent in the wound site. Antibacterial and antifungal effects have also been reported for the A. vera gel (27).

\section{Cydonia oblonga}

In the study of Alizadeh et al. (28) on skin burn infections due to $S$. aureus, the antimicrobial effect of Cydonia oblonga in the process of burn wound healing was demonstrated. Regarding the effect of C. oblonga ointment in improving the skin wounds in humans; it seems that the effect of this herb in reducing skin inflammation and improving burn wounds is mainly due to active ingredients in its mucilage (29). The results of microscopic and macroscopic evaluation of Tajedini et al. (30) showed that the extract of $C$. oblonga had a significant effect on the healing process of wound burns by increasing tissue proliferation, proliferating fibroblast cells and reducing edema and inflammation in the burn wound area. After C. oblonga treatment, the process of regenerating the epithelial cells is greater and the extent of the fibrotic reaction is greater, and edema and inflammation in the burn area are lower. The extract has antioxidant and anti-inflammatory properties and repairs and disinfects the wound (30).

\section{Scrophularia striata}

Studies have shown that $S$. striata and its compounds have effects on necrosis factors, tumorigen and interferon, which reduces edema and cell infiltration and reduces the proliferation of T lymphocytes (31). Another study found that the presence of phenylpropanoidin glycosides inhibited the activity of macrophages thereby inhibiting the production of inflammatory chemical intermediates and ultimately reducing inflammation (32). The results of a study showed that the active ingredients of $S$. striata had a significant effect on the process of wound healing by increasing the angiogenesis and synthesis of collagen and reducing muscle involvement in comparison with other groups. Stimulation of fibroblast cell growth, the antioxidant and antiinflammatory properties of $S$. striata confirm the effect of this plant on burn wound healing by stimulating collagen production and faster contraction of the wound, angiogenesis and vasodilation (33). In addition, antibacterial properties of phenolic acids are another reason for the effectiveness of the plant in healing skin wounds (34).

\section{Centella asiatica}

Centella asiatica at a low dose caused an increase in the levels of monocyte chemoattractant protein 1 (MCP-1), vascular endothelial growth factor, and interleukin beta-1 in burn wounds. Increase in angiogenesis induced by vascular endothelial growth factor following increased expression of MCP-1 in keratinocytes and increased expression of interleukin beta- 1 resulted in an increase in the process of burn wound healing in the group treated with the plant extract (35). In the study of Wu et al. (36), the effect of triterpenoid compounds including glycosides (madecassoside and asiaticosides) and madecassic acid and asiatic acid aglicans in $C$. asiatica extract increased the synthesis of collagens 1-3 of the fibroblast cells by increasing the synthesis of fibroblast growth factor, thereby causing an increase in the process of burn wound healing in the groups treated with the extract of the plant compared with the control group.

\section{Arnebia euchroma}

It has been established that A. euchroma is useful for improving skin burns and injuries (37). The study of Ogurtan et al. (38) on the healing of burn wounds in rabbits, showed that except for extremely severe burns, other cases completely healed by A. euchroma. The study of Nasiri et al. (39) showed that the effect of the A. euchroma ointment on burn wound healing effectively prevented the secondary complications of burn, including inflammation and wound secretion or infection, probably due to antibacterial properties of the plant. The results of Aliasl et al. (40) showed that A. euchroma has significant effects on the progression of epithelization, proliferation of fibroblast cells, the synthesis of collagen strands and angiogenesis in damaged tissue due to antibacterial and antimicrobial properties.

\section{Calendula officinalis}

Oral use of the $C$. officinalis extract improves the process of skin burn wound healing by strengthening the antioxidant defense mechanisms (41). The antioxidant mechanism, acute phase proteins and granulation in skin burns indicated an increase in hexosamine and hydroxyproline of collagen in the burn area. In addition acute-phase proteins including heptoglobin and orosomucoid which increase in burn injury were significantly reduced after treatment with this extract (42).

\section{Hypericum perforatum}

$H$. perforatum extract accelerated burn wound healing due to the antioxidant properties of tannin and its effect on increasing the proliferation of burn wound healing has been accelerated by TNF fibroblast cells and high secretion compared to 
other groups and reduced the length of wound healing (43). This plant accelerated progression of the burn wound healing process by reepithelization and increasing expression of vascular endothelial growth factor and transforming growth factor- $\beta$ (44).

\section{Discussion}

Burns are a kind of damage to skin and the underlying tissues caused by heat, electricity, chemicals, friction, or radiation. Although large burns can lead to death, new treatments that have been invented since the 1960s have significantly reduced death from burn, especially in children and adolescents (45).

Variety of chemical compounds present in medicinal plants accelerate wound healing. The most important compounds of Arnebia euchroma are the combination of shikonin and alkannin (46). The Camellia sinensis contains caffeine, catechins, and flavonoids (47). The most important compounds of Scrophularia striata plants are iridoid glycosides, aucubin and catalpol (48). The Cydonia oblonga contain mucilages, lipids, alcohols, resins and tannins (49). Among the compounds of Calendula officinalis flowers of the spring contains flavonoids, coumarins, saponins, volatile oils, carotenoids and amino acids (50). The chemical elements that make up the Centella asiatica include triterpenoids, glycosides and phenolic compounds (51).

\section{Conclusion}

The review has brought out several indigenous plants of Iran which are effective on the restoration process of the burn wounds. All these plants accelerate wound healing process due to substantial anti-inflammatory activity, increased epithelization, increased fibroblast cell proliferation, increased antioxidant activity, collagen synthesis and angiogenesis.

\section{Acknowledgements}

We are grateful for the support from Research and Technology Deputy of Lorestan University of Medical Sciences, Khorramabad, Iran.

\section{Authors' contribution}

MS and SA have done the collection of literature. All authors (MS, GB, AH and SA) prepared the content of the manuscript, provided inputs, and approved the final version.

\section{Competing Interest}

The authors declare that they have no competing interest.

\section{References}

1. Draf W. Die chirurgische Behandlung entzündlicher Erkrankungen der Nasennebenhöhlen. Indikation, Operationsverfahren, Gefahren, Fehler und Komplikationen, Revisionschirurgie. [Surgical treatment of the inflammatory diseases of the paranasal sinuses. Indication, surgical technique, risks, mismanagement and complications, revision surgery]. Arch Otorhinolaryngol. 1982;235(1):133-305. https://doi.org/10.1007/BF00458469

2. Vinothapooshan G, Sundar K. Wound healing effect of various extracts of Adhatoda vasica. International Journal of Pharma and Bio Science 2010;1:530-536.

3. Bahadori M. [Pathology and staining methods]. Tehran University Pub. 1990; p. 216-17 (Persian).

4. Nasiri E, Hoseini Mehr S, Azadbakht M, Madani S. Survey of the burn wound healing by Iranian traditional medicine from the herbalists or herbal medicine vendors in the Mazandaran province. J Med Plants 2013;12(48):136-49.

5. Forjuoh SN. Burns in low- and middle-income countries: a review of available literature on descriptive epidemiology, risk factors, treatment and prevention. Burns https://doi.org/10.1016/j.burns.2006.04.002

6. Seyyedi M. Burns. $1^{\text {st }}$ Ed. Tehran: Eshtiagh; 1997; p. 24-26 [in Persian].

7. Malekmohammadi M, Abdol Tehrani H, Aghdami N. Skin structure and wound healing phases. Dermatol Cosmet. 2011;2(4):229-244.

8. Holmes JH, Heimbach DM. Burns. In: Brunicardi FC, Andersen DK, Billiar TR, Dunn DL, Hunter JG, Pollock RE. Schwartz's Principles of Surgery. $8^{\text {th }}$ Ed. New York: McGraw- Hill: 2005; p. 204-28.

9. Abbaspour A. Burn emergencies. $1^{\text {st }}$ Ed. Abbaspour; 1996; p. 41-43 [in Persian].

10. Wyatt D, McGowan DN, Najarian MP. Comparison of a hydrocolloid dressing and silver sulfadiazine cream in the outpatient management of second degree burns. J Trauma 1990;30(7):857-867. $\quad$ https://doi.org/10.1097/00005373$\underline{199007000-00016}$

11. Huong JS, Wang YH, Ling TY, Chuang SS, Johnson FE, Huang SS. Synthelic TGF antagoniset accelerates wound healing and reduces scarring. The FASEB Journal 2002;16:1269-1270. https://doi.org/10.1096/fj.02-0103fje

12. Froushani SMA, Zarei L, Ghaleh HEG, Motlagh BM. Estragole and methyl-eugenol-free extract of Artemisia dracunculus possesses immunomodulatory effects. Avicenna Journal of Phytomedicine 2016;6(5):526-534.

13. Abbasi N, Azizi Jalilian F, Abdi M, Saifmanesh M. A comparative study of the antimicrobial effect of Scrophularia striata Boiss. extract and selective antibiotics against Staphylococcus aureus and Pesudomonas aeruginosa. Journal of Medicinal Plants 2007;6 (SUPPL. 1): 10-18.

14. Bahmani M, Khaksarian M, Rafieian-Kopaei M, Abbasi N. Overview of the therapeutic effects of Origanum vulgare and Hypericum perforatum based on Iran's ethnopharmacological documents. Journal of Clinical and Diagnostic Research 2018;12(7):1-4. https://doi.org/10.7860/ ICDR/2018/34177.11728

15. Shokri Z, Khoshbin M, Koohpayeh A, Abbasi N, Bahmani F, Rafieian-Kopaei, M, Beyranvand F. Thyroid diseases: Pathophysiology and new hopes in treatment with medicinal plants and natural antioxidants. International Journal of Green Pharmacy 2018;12(3):473-482.

16. Abbasi N, Mohammadpour S, Karimi E, Aidy A, Karimi P, Azizi M, Asadollahi K. Protective effects of Smyrnium 
cordifolium Boiss essential oil on pentylenetetrazolinduced seizures in mice: Involvement of benzodiazepine and opioid antagonists. Journal of Biological Regulators and Homeostatic Agents 2017;31(3):683-689.

17. Tajbakhsh M, Karimi A, Tohidpour A, Abbasi N, Fallah F, Akhavan MM. The antimicrobial potential of a new derivative of cathelicidin from Bungarus fasciatus against methicillin-resistant Staphylococcus aureus. Journal of Microbiology https://doi.org/10.1007/s12275-018-7444-5

18. Bahmani M, Taherikalani M, Khaksarian M, RafieianKopaei M, Ashrafi B, Nazer M, Soroush S, Abbasi N, Rashidipour M. The synergistic effect of hydroalcoholic extracts of Origanum vulgare, Hypericum perforatum and their active components carvacrol and hypericin against Staphylococcus aureus. Future Sci OA. 2019;5(3):FSO371. https://doi.org/10.4155/fsoa-2018-0096

19. Pirbalouti AG, Azizi S, Koohpayeh A, Hamedi B. Wound healing activity of Malva sylvestris and Punica granatum in alloxan-induced diabetic rats. Acta Pol Pharm. 2010; 67(5):511-516.

20. Barros L, Carvalho AM, Ferreira IC. Leaves, flowers, immature fruits and leafy flowered stems of Malva sylvestris: a comparative study of the nutraceutical potential and composition. Food Chem Toxicol. 2010;48(6):1466-1472. $\quad$ https://doi.org/ 10.1016/j.fct.2010.03.012

21. Ghasemi Pirbalouti AG, Yousefi M, Nazari H, Karimi I, Koohpayeh A. Evaluation of burn healing properties of Arnebia euchroma and Malva sylvestris. Electronic Journal of Biology 2009;5(3):62-66.

22. Nasiri E, Hosseinimehr SJ, Azadbakht M, Akbari J, EnayatiFard R, Azizi S. The healing effect of Arnebia euchroma ointment versus silver sulfadiazine on burn wounds in rat. World J Plast Surg. 2015;4(2):134-44. https://doi.org/10.1515/jcim-2014-0068

23. Asadi S, Zamiri A, Ezzati S, Parsaei P, Rafieian M, Shirzad H. [Effect of alcoholic extract of green tea (Camellia sinensis) on the healing process in surgical and burn wounds in rats]. J Birjand Univ Med Sci. 2011;18(1):1-9.

24. Fatemi MJ, Nikoomaram B, Rahimi AA, Talayi D, Taghavi $S$, Ghavami Y. Effect of green tea on the second degree burn wounds in rats. Indian Journal of Plastic Surgery 2014;47(3):370.

25. Malekhosseini A, Ghaffarzadegan $R$, Alizadeh $S A$, Ghaffarzadegan RR, Haji Agaei R, Ahmadlou M. [Effect of aloe vera gel, compared to $1 \%$ silver sulfadiazine cream on second-degree burn wound healing]. Complement Med J Fac Nurs Midwifery 2013;3(1):418-28.

26. Heck E, Head M, Nowak D, Helm P, Baxter C. Aloe vera (gel) cream as a topical treatment for outpatient burns. Burns 1981;7(4):291-94. https://doi.org/10.1016/03054179(81)90112-1

27. Klein AD, Penneys NS. Aloe vera. J Am Acad Dermatol. 1988;18(4):714-720. 9622(88)70095-X

28. Alizadeh H, Rahnema M, Nasiri Semnani S, Ajalli $M$, Rostamkhani R. Effect of Cydonia oblonga seed's extract and silver nanoparticles on wound healing in mice infected with Staphylococcus aureus] JBUMS. 2013;5(1):3238.

29. Mousavi Z, Meshki M, Hemmati A, Salehi Veisi M, Rafiei R. [Evaluation of the efficacy of Quince mucilage on wound healing]. Iran J Dermatol. 2006;9(3):260-3.

30. Tajoddini A, Rafieian-kopaei M, Namjoo A, Sedeh M, Ansari R, Shahinfard N. [Effect of ethanolic extract of Cydonia oblonga seed on the healing of second-degree burn wounds]. Armaghane Danesh. 2013;17(6):494-501.
31. Bas E, Recio MC, Abdallah M, Máñez S, Giner RM, CerdáNicolás M, Rios J. Inhibition of the pro-inflammatory mediators' production and anti-inflammatory effect of the iridoid scrovalentinoside. J Ethnopharmacol. 2007;110(3):419-427.

https://doi.org/10.1016/j.jep.2006.09.038

32. Díaz AM, Abad MJ, Fernández L, Silván AM, De Santos J, Bermejo P. Phenylpropanoid glycosides from Scrophularia scorodonia: in vitro anti-inflammatory activity. Life Sci. 2004; 74(20):2515-2526 https://doi.org/10.1016/j.lfs.2003.10.008

33. Tanideh N, Haddadi MH, Rokni-Hosseini MH, Hossienzadeh M, Mehrabani D, Sayehmiri K, KoohiHossienabadi O. The healing effect of Scrophularia striata on experimental burn wounds infected to Pseudomonas aeruginosa in rat. World journal of Plastic Surgery 2015;4(1):16

34. Fernández MA, García MD, Sáenz MT. Antibacterial activity of the phenolic acids fractions of Scrophularia frutescens and Scrophularia sambucifolia. J Ethnopharmacol. https://doi.org/10.1016/0378-8741(96)01419-5

35. Kimura Y, Sumiyoshi M, Samukawa K, Satake N, Sakanaka M. Facilitating action of asiaticoside at low doses on burn wound repair and its mechanism. Eur J Pharmacol. 2008;584(2-3):415-423.

https://doi.org/10.1016/j.ejphar.2008.02.036

36. Wu F, Bian D, Xia Y, Gong Z, Tan Q, Chen J, Dai Y. Identification of major active ingredients responsible for burn wound healing of Centella asiatica herbs. Evid Based Complement Alternat Med. 2012;848093. https://doi.org/10.1155/2012/848093

37. $\mathrm{Fu}$ XO, Lu DW. Stimulation of shikonin production by combined fungal elicitation and in situ extraction in suspension cultures of Arnebia euchroma. Enzyme Microb Technol. 1999;24(5):243-246. https://doi.org/10.1016/S0141 0229(98)00104-5

38. Ogurtan Z, Hatipoglu F, Ceylan C. The effect of Alkanna tinctoria Tausch on burn wound healing in rabbits. Dtsch Tierarztl Wochenschr. 2002;109(11):481-485.

39. Nasiri E, Hosseinimehr SJ, Azadbakht M, Akbari J, EnayatiFard R, Azizi S, Azadbakht M. The healing effect of Arnebia euchroma ointment versus silver sulfadiazine on burn wounds in rat. World J Plast Surg. 2015;4(2):134-144. https://doi.org/10.1515/jcim-2014-0068

40. Aliasl J, Barikbin B, Khoshzaban F, Naseri M, Sedaghat R, Kamalinejad M, Talei D, Emadi F, Akbari Z, Aliasl F, Jalaly NY. Effect of Arnebia euchroma ointment on post-laser wound healing in rats. J Cosmet Laser Ther. 2015;17(1):4145. https://doi.org/10.3109/14764172.2014.968583

41. Bahramsoltani R, Farzaei MH, Rahimi R. Medicinal plants and their natural components as future drugs for the treatment of burn wounds: an integrative review. Arch Dermatol Res. 2014;306(7):601-617. https://doi.org/10.1007/ s00403-014-1474-6

42. Chandran PK, Kuttan R. Effect of Calendula officinalis flower extract on acute phase proteins, antioxidant defense mechanism and granuloma formation during thermal burns. J Clin Biochem Nutr. 2008;43(2):58-64. https://doi.org/10.3164/jcbn.2008043

43. Momeni E, Aroi N, Aroi M, Jafari Barmak M, Mahmoudi R, Malekzadeh JM, Mohammadi J, Talebianpour MS, Mohammadi R, Mohammad Hosseini S. [The effect of Hypericum perforatum extract and 1\% silver sulfadiazine on second degree burn wound healing in male rats]. Armaghane-danesh. 2014;19(7):625-632.

44. Sayar H, Gergerlioglu N, Seringec N, Ozturk P, Bulbuloglu E, Karabay G. Comparison of efficacy of topical phenytoin with hypericin in second-degree burn wound healing: an 
experimental study in rats. Med Sci Monit Basic Res. 2014;20:36-46. https://doi.org/10.12659/MSMBR.890337

45. Herndon D. Total burn care. $4^{\text {th }}$ Ed. Edinburgh: Saunders. S. 2012.

46. Papageorgiou VP, Assimopoulou AN, Ballis AC. Alkannins and shikonins: a new class of wound healing agents. Current Medicinal Chemistry 2008;15(30):3248-3267. https://doi.org/10.2174/092986708786848532

47. Barros L, Carvalho AM, Ferreira IC. Leaves, flowers, immature fruits and leafy flowered stems of Malva sylvestris: a comparative study of the nutraceutical potential and composition. Food Chem Toxicol. 2010;48(6):1466-1472. https://doi.org/10.1016/j.fct.2010.03.012

48. Lee JY, Jang YW, Kang HS, Moon H, Sim SS, Kim CJ. Antiinflammatory action of phenolic compounds from Gastrodia elata root. Arch Pharm Res. 2006;29(10):849858. https://doi.org/10.1007/BF02973905
49. Kourounakis AP, Assimopoulou AN, Papageorgiou VP, Gavalas A, Kourounakis PN. Alkannin and shikonin: effect on free radical processes and on inflammation - a preliminary pharmacochemical investigation. Arch Pharm 2002;335(6):262-266. https://doi.org/10.1002/15214184(200208)335:6\%3C262::AID-ARDP262\%3E3.0.CO;2-Y

50. Nie S, Xie M, Fu Z, Wan Y, Yan A. Study on the purification and chemical compositions of tea glycoprotein. Carbohydrate Polymers 2008;71(4):626-633. https://doi.org/ 10.1016/j.carbpol.2007.07.005

51. Muley BP, Khadabadi SS, Banarase NB. Phytochemical constituents and pharmacological activities of Calendula officinalis Linn (Asteraceae): a review. Trop J Pharm Res. 2009;8(5):455-465. https://doi.org/10.4314/tjpr.v8i5.48090 